\title{
Rituales de cráneos y enterramiento en el Neolítico precerámico del Próximo Oriente.
}

\author{
Isabel Rubio de Miguel \\ Departamento de Prehistoria y Arqueología \\ Universidad Autónoma de Madrid
}

\section{Resumen}

El estudio de los cráneos hallados en los yacimientos natufienses y sobre todo precerámicos del Próximo Oriente se ha visto ampliado por su número, pero también por las posibilidades de análisis desarrolladas desde la aparición de los primeros en las excavaciones de K. Kenyon en Jericó. La diversidad de lugares de aparición y de tratamiento de los cráneos permite replantearse o ampliar las interpretaciones iniciales, centradas en el culto a los antepasados. Los hallazgos de cráneos, modelados o no, no pueden desligarse del florecimiento del mundo simbólico en el PPNB ni, en ocasiones, del enterramiento. La Etnoarqueología suministra igualmente posibilidades de interpretación que deben ser tenidas en cuenta, ya que también en poblaciones actuales se documentan ritos que implican la manipulación de cráneos y otros restos.

Palabras clave: Próximo Oriente, Precerámico, Cráneo, Ritual, Etnoarqueología.

\section{Summary}

The study of skulls found in natufian and mostly preceramic near eastern settlements has been enlarged because of their number, but also because of the possibilities of analysis developed since the first finds in K. Kenyon's excavations at Jericho. The diversity of discovery places and of skulls treatment allows rising again or enlarging the initial interpretations, focused on ancestor's cult. But skulls finds, plastered or not, can't be separated of the symbolic world flourishing in PPNB, or of burials, sometimes. Ethnoarchaeology offers possibilities of interpretation as well, which must be taken into account, because in living communities documented rites also imply the manipulation of skulls and other bones.

Keywords: Near East, Preceramic, Skulls, Ritual, Ethnoarchaeology.

Si algo distinguía a la Dra. M ${ }^{\mathrm{a}}$ Rosario Lucas Pellicer, a quien dedicamos este homenaje, era su interés por los más variados aspectos del pasado, pero particularmente por aquellos que podrían considerarse no convencionales y que sin embargo nos acercan de forma especial a los seres humanos que vivieron en esas etapas pretéritas.

1 Abordé por primera vez estos aspectos en una contribución a un ciclo de lecciones sobre el Próximo Oriente (Rubio, e.p.) celebrado en la U.A.M. Los nuevos descubrimientos y análisis practicados, además de los enfoques
El que hoy denominamos "mundo simbólico" de nuestros antepasados interesó siempre vivamente a la Dra. Lucas, Charo para quienes tuvimos la suerte de disfrutar de su saber y sobre todo de su amistad. Esa es la razón por la que he elegido el tema ${ }^{1}$ que da título a estas páginas para participar en el citado homenaje, lamentado profundamen-

actualmente aplicados al estudio de los cráneos permiten volver sobre el tema y ofrecer explicaciones alternativas a este interesante fenómeno ritual. 
te no poder ya debatir con ella sobre el mismo, como hicimos sobre tantos otros igualmente atrayentes. Sirvan pues estas líneas como afectuoso recuerdo y homenaje a la profesora, y sobre todo amiga, desaparecida.

Desde la formulación del concepto de Revolución Neolítica por V.G. Childe, se han venido valorando distintos factores en el proceso que supone la aparición de la economía de producción, esto es, la adopción de la agricultura y de la ganadería y el establecimiento de nuevas relaciones entre el hombre y su entorno, pero también de una nueva sociedad y de otras creencias. La investigación sobre el origen del Neolítico se ha considerado equivalente en muchas etapas de la misma a la del nacimiento de la agricultura y, en ese sentido, canalizaron las explicaciones del citado proceso diversos investigadores: R. Braidwood, K. Flannery, L. Binford y M.N. Cohen. Pero, a partir de un cierto momento, las motivaciones de tipo social pasaron, paralelamente, a un primer plano (B. Bender, A. Testart o T. Ingold). Sólo más recientemente, se ha sugerido que la ideología y el pensamiento pudieron preceder y propiciar la aparición de la agricultura o que constituyeron en realidad los elementos clave del Neolítico (I. Hodder y J. Cauvin), que éste suponía la introducción de una nueva "ética" (A. Whittle), que era un sistema conceptual para ordenar el mundo (J. Thomas), o que los cambios ideológico y económico se reforzaron mutuamente ( $\mathrm{R}$. Bradley).

Sin embargo, no me propongo aquí terciar sobre la validez de ésta o aquella teoría sobradamente conocidas, aunque alguna de ellas se halle directamente relacionada con la interpretación de determinados restos que veremos, sino abordar uno de los muchos aspectos del ritual, y acaso del enterramiento, de determinados grupos neolíticos del Próximo Oriente. Los cráneos separados del cuerpo, modelados o no, no pueden a mi juicio desligarse en su interpretación del mundo sepulcral ni del ámbito religioso, como tampoco, por otra parte, de las restantes parcelas de la vida (y muerte) de estas comunidades, en las que aquí no podemos entrar debido a la obligada extensión del artículo. Por ello, me centraré exclusivamente en dichos testimonios (para el

2 Algunos autores (Aurenche y Kozlowski, 1999) adoptan la periodización establecida por el ASPRO (Atlas des sites du Proche Orient), elaborado por los investigadores resto, ver el Cuadro 2). Por idéntico motivo no podré detenerme en la descripción de los distintos hallazgos que pueden consultarse en los Cuadros 3, 4 y 5.

Pero ante todo, es preciso poner de relieve algo que puede parecer obvio y es que el Próximo Oriente no es una región culturalmente homogénea. En ese sentido, se han establecido una serie de áreas culturales (Figura 1) que así lo señalan. Es preciso tener en cuenta además que los avatares experimentados por la investigación han condicionado en gran medida los datos que poseemos sobre las distintas zonas del Próximo Oriente, otorgando un mayor peso específico a Levante en detrimento de otras en las que las intervenciones bélicas han imposibilitado la investigación, previsiblemente también para el futuro, como es el caso de Irak.

\section{LAS SOCIEDADES DE CAZADORES-RECO- LECTORES PRECEDENTES (12000-10300 cal.BC) ${ }^{2}$}

Los grupos de cazadores-recolectores que desarrollan su vida en el Próximo Oriente entre los 12000 y los 10300 años cal.BC (periodo $1 \mathrm{del}$ ASPRO), aproximadamente, muestran en el estado actual de nuestros conocimientos una evidente regionalización, siendo la zona de Levante la más estudiada y, por tanto, la mejor conocida (Aurenche y Kozlowski, 1999, 18-19).

Las comunidades del Natufiense, la cultura más claramente definida, parecen haber asociado sus sepulturas únicamente a los poblados sedentarios (Aurenche y Kozlowski, 1999, 28), mientras que los enterramientos secundarios corresponderían al patrón estacional o semisedentario de algunos de los grupos, lo que implicaría el traslado de los cadáveres en un momento dado (Perrot en Mellaart, 1975, 37). J. Mellaart (1994) consideraba que era posible reconocer una jerarquía social entre la gente enterrada en los yacimientos natufienses. Los hallazgos de cráneos con y sin mandíbula son raros en el Natufiense antiguo, convirtiéndose en una costumbre hacia el final de la cultura en determinados yacimientos (Valla, 1995, 176). En algún caso, la mandíbula se incluye en enterramientos como el de Erq el Ahmar, donde un esqueleto entero

de la "Maison de l'Orient" (Lyon), que, en parte, emplearemos aquí como ya hemos hecho en otras ocasiones, remitiendo en adelante al Cuadro 1. 
se hallaba depositado junto con fragmentos de mandíbulas de otros seis individuos.

La mención a estas sociedades, precedente inmediato de las neolíticas, resulta esencial porque en ellas surgen algunas de las características desarrolladas posteriormente. En el ámbito funerario, resulta evidente que en esos momentos no existe un rito único para la población natufiense ni seguramente para sus vecinos, lo que posiblemente podría explicarse por la referida regionalización y por tratarse de grupos caracterizados por una destacada movilidad. Las diferencias de status, sugeridas por J. Mellaart mediante el análisis de los ajuares, podrían igualmente deducirse a partir del lugar donde se practicaron los enterramientos, de las características de éstos o de su misma existencia, ya que quizá no todos los miembros del grupo fueron objeto del citado ritual. Sin embargo, en mi opinión, no parecen evidenciarse tan claramente tales desigualdades, pudiendo pensarse, en todo caso, que la diferenciación señalada se halla en relación con la edad o el sexo, por ejemplo. No obstante, no puede descartarse que algunos de estos grupos pudieran haber generado ya un comportamiento similar al de las sociedades agrícolas, como se defiende actualmente para algunos cazadores-recolectores especializados con almacenamiento y sedentarismo, que presentan desigualdades sociales evidentes.

\section{LOS PRIMEROS MOMENTOS DEL NeOLÍtico (10300-8800 CAL.BC) ${ }^{3}$}

En relación con el tema que analizamos, la innovación principal en el PPNA es el aumento de los cráneos separados del cuerpo, que no presentan ningún tipo de modelado, para los que cabría hacer una triple distinción: su localización en enterramientos, aislados o en depósitos aparentemente sin relación con el mundo funerario. Por lo que respecta al enterramiento, se documenta toda la diversidad de tratamiento anterior, con ciertos matices. En Hatoula, algunos de los esqueletos procedentes de enterramientos primarios asociados al hábitat se depositaron sin cráneo. Además de los citados enterramientos primarios, se documentaron otros secundarios en silos, con huesos y cráneos coloreados con ocre rojo (en un caso con dieciséis esqueletos de los

3 Periodo 2 del ASPRO. En la actualidad, se replantea el PPN y, en especial, el PPNA para el que se defiende una entidad cronológica pero no económica. Se prefiere, en que sólo tres conservaban el cráneo).

En opinión de I. Kuijt y N. Goring-Morris (2002, 376), en este periodo y en el PPNB medio, los cráneos se retiraban después de la descomposición de los tejidos, excavando un área alrededor de los mismos para extraerlos del enterramiento primario, rellenando después el agujero. Seguramente, se preparaban para uso de la comunidad y después eran vueltos a enterrar en un acontecimiento comunitario fuera, dentro o en áreas señaladas del yacimiento, como una forma de afirmar la cohesión de la comunidad y las creencias domésticas y colectivas.

Otras regiones han suministrado igualmente datos sobre el mundo funerario, pero en ningún caso se han atestiguado decapitaciones o depósitos de cráneos aislados. Es preciso recordar que, por el momento, no se conocen establecimientos precerámicos correspondientes a esta etapa en la llanura aluvial mesopotámica, ya que todos los anteriores al 6500 a.C. se ubican al pie de los montes Zagros en el Kurdistán. Recordemos una vez más que manejamos fundamentalmente datos de Levante, la Yazira y algunos, escasos, de los Zagros.

Conviene destacar también los cambios que experimenta en general el mundo simbólico del PPNA, donde encontramos nuevas representaciones figuradas, con variantes regionales. En la zona objeto de estudio, se han hallado además plaquetas decoradas con signos que parecen sugerir pictogramas, así como piedras con ranuras de función desconocida (¿simbólica?), aunque pudiera ser utilitaria. Aunque santuarios como el que se había querido reconocer de Jericó se descartan hoy, cabe hacer alusión a la existencia de un edificio "especial" en Tell Mureybet III (con un enterramiento en cuyo ajuar había un puñal de obsidiana). En Nemrik, la casa 6, que albergaba una inhumación doble, parece haber sido construida con ese fin. Los cuerpos estaban sobre el suelo junto con una estatuilla (bâton poli) adornada con una cabeza humana (Aurenche y Kozlowski, 1999, 49). ¿ Podría interpretarse el enterramiento de Mureybet como el de un "especialista" religioso? Igualmente, cabe recordar las estructuras distintas del hábitat, de planta circular, probablemente comunales, halladas en este mismo yacimiento y en el de Jerf el Ahmar (Siria) (Stordeur $e t$ alii, 2000).

este momento, aludir a las diversas culturas que se han identificado, con sus distintas duraciones y desarrollos. 


\section{El AFIANZAMiento del NeOlítico: EL PPNB (8800-6900 CAL.BC)4}

Por un lado, habría que mencionar los cráneos relacionados con el mundo funerario (Cuadro 4) y, por otro, los hallados en ámbitos distintos, aislados o en depósitos (Cuadro 5). El modelado es una de las principales innovaciones del momento, persistiendo todavía en distintas ocasiones la ausencia del mismo. Pero, como en el caso anterior, también hay que tener en cuenta los enterramientos de cuerpos decapitados. Se documentan igualmente otro tipo de manipulaciones. A ese respecto, Y. Garfinkel $(1994,165)$ opina que los cráneos habrían experimentado la extracción deliberada de los dientes para proporcionar características gerontomórficas alusivas al gobierno y la ancianidad de los más viejos.

Una de las novedades más destacadas en la investigación de los cráneos tiene que ver con la tecnología empleada en su preparación. Se han practicado análisis en ejemplares de Jericó, Kfar Hahoresh, Beisamoun, 'Ain Ghazal y Tell Ramad atestiguándose la uniformidad de conceptos generales y de determinados aspectos tecnológicos, pero también la diversidad entre yacimientos, lo que indicaría la existencia de tradiciones específicas en cada uno de ellos, por lo que los cráneos de un mismo yacimiento presentan tratamientos similares (Bonogofsky, 2001 y Goren, Goring-Morris y Segal, 2001). Lo mismo sucede con respecto a las estatuas antropomorfas de barro y arcilla, como las halladas en 'Ain Ghazal (Kuijt y Goring-Morris, 2002) (Figura 5). Conocemos en detalle las distintas técnicas empleadas en los procesos de modelado-enlucido de los cráneos, que incluyen el uso del fuego para proporcionar una mayor duración a la pieza, en las que por razones de espacio no podemos detenernos. En todo caso, aparecen resumidas en la Figura 3, A.

Determinadas particularidades han llevado a algunos autores (Goren, Goring-Morris y Segal, 2001, 686) a defender que los cráneos no serían retratos de difuntos. La falta de mandíbula, que se mantiene en Ramad y que proporciona un aspecto irreal al rostro, sería uno de ellos, así como el hecho de que los rasgos de la cara no corresponden a su situación anatómica. Sin

4 El PPNB (periodos 3 y 4 del ASPRO) se ha dividido en tres etapas: Antiguo (8800/8600-8200 cal.BC), Medio (8200-7500 cal.BC) y Final (7500-7000/6900 cal.BC). El denominado PPNC, definido hace pocos años, se ha datado entre el 7000-6200 cal.BC. En este momento, embargo, en un cráneo de Jericó, la mandíbula ha sido reconstruida en yeso y cabe recordar que también a un ejemplar del mismo yacimiento se le ha pintado un bigote. Otro de 'Ain Ghazal parece resultar más real, lo mismo que el Homo 1 de Kfar Hahoresh que presenta el mentón hendido. La explicación que se ha dado a las diferencias entre yacimientos es que las técnicas se difundieron sin que el artesano se desplazase de uno a otro lugar. Por lo que se refiere a este especialista, se plantea su existencia misma, pero también la posibilidad de que hubiera podido jugar otro papel en la comunidad (¿chamán?), proponiéndose la posible existencia de una especialización artesana incipiente (Goren, Goring-Morris y Segal, 2001, 688).

La distribución geográfica de estos hallazgos evidencia otra diferenciación más. Los modelados parecen limitarse a Levante sur, pero los aislados, sin tratamiento particular se encuentran hasta en los valles altos del Tigris y el Éufrates, sin que esta práctica haya llegado a los Zagros, aparentemente. Para Hershkovitz y otros investigadores $(1995,780)$, precisamente los cráneos constituyeron uno de los rasgos de la koiné que se ha querido ver en el PPNB (Aurenche y Kozlowski, 1999). Sin embargo, cabe recordar que aparecen con anterioridad y que tampoco se hallan en todas las áreas del Próximo Oriente. No obstante, la distribución antes apuntada podría suponer la expansión de la idea hacia el este, en relación quizá con intercambios a larga distancia, paralela a una evolución de la misma en el área levantina.

Procedentes del PPNB de Levante, se han hallado 61 cráneos modelados/enlucidos. Corresponden a hombres, mujeres y niños, se entierran solos o junto con otros, están modelados/decorados, decorados sólo con pintura o aparecen sin decorar (Bonogofsky, 2001, 144). Durante el PPNB antiguo parece haber una continuidad de las prácticas anteriores y en el PPNB medio, se documentan entre otros casos enterramientos infantiles en tumbas sencillas, a veces sin cráneo, junto con adultos con cráneo ('Ain Ghazal) y en contextos rituales, así como la alteración secundaria de algunos cráneos de adultos de los enterramientos primarios, usados y vueltos a enterrar (Kuijt y Goring-Morris, 2002, 410-411).

comienza a aparecer la cerámica en el norte de Siria y en la estepa mesopotámica en torno al 7000 cal.BC, mientras que Palestina y Siria meridional continúan siendo acerámicos hasta el 6500 cal.BC (final del periodo 5 del ASPRO). A esta fase corresponde Çatal Hüyük. 
En el PPNB final, los datos son mucho menos numerosos.

Elementos muy posiblemente relacionados con los cráneos son las máscaras. Las encontradas en la cueva de Nahal Hemar son caras esculpidas con los ojos y la boca marcados por cavidades (Figura 4,4). Parecen objetos destinados a ser fijados a alguna parte por el abombamiento que presentan y los agujeros laterales. Según O. Bar-Yosef y D. Alon (1992), algunas muestran testimonios de la existencia de materias adhesivas quizá para fijar una peluca. También en 'Ain Ghazal se encontró una variante, posiblemente destinada a ser adosada a cráneos humanos, habiéndose hallado las máscaras enterradas, pero separadas de los cráneos correspondientes, en una fosa dispuesta al efecto.

Por lo que respecta a otros aspectos del mundo simbólico, habría que citar que bajo ciertos edificios, considerados por algunos autores "casas de los muertos" a escala de la comunidad tal como se constata en Etnografía, se practicaron enterramientos colectivos. Según M. Molist (1992), estos hechos y particularmente el enterramiento asociado a la vivienda demostrarían que la idea de familia fue ganando terreno frente a la de clan de las sociedades de cazadores-recolectores precedentes. Se ha avanzado la hipótesis de que únicamente se enterrarían aquellas personas que tuvieran descendencia. Serían los casos de Nemrik III, Tell Aswad o Tell Halula, entre otros. G.O. Rollefson $(1998,57)$ ha señalado que estos edificios de 'Ain Ghazal y de otros yacimientos sirvieron para ceremonias públicas y semipúblicas (según su tamaño) y que, seguramente, la construcción de los más grandes contribuiría a cohesionar la sociedad. Responsabiliza de la celebración de rituales, posiblemente estacionales, relacionados con el linaje, a chamanes que podrían tener una dedicación parcial o a tiempo completo. En Çatal Hüyük, por ejemplo, se percibe una diferenciación entre los enterramientos practicados bajo el suelo de las casas y los de los santuarios de los niveles inferiores ("enterramientos con ocre"), dotados de ricos ajuares. Así pues, paralelamente a las viviendas se documentan otras estructuras destinadas al culto, como los de 'Ain Ghazal, Çayönü, Göbekli, quizá Bouqras y Zaghe y, por supuesto, los numerosos santuarios de Çatal Hüyük. Por otra parte, se atestigua la intensificación y la variedad de la producción de figuritas de diverso tipo.

En 'Ain Ghazal, apareció una treintena de estatuas, enterradas en dos fosas, dispuestas en estratos superpuestos, de cuerpo entero con un armazón de cañas o sólo la cabeza sobre un busto estilizado, con incrustación de betún en los ojos y pintura (Figura 5). Algunas de ellas son bicéfalas. Determinados ejemplares presentaban seis dedos, lo que, como se sabe, constituye una anomalía genética; sin embargo se ignora si aquí se ha querido representar esto exactamente. La parte posterior de las mismas era lisa y plana como para ser adosadas. Estos hallazgos han provocado una nueva lectura de los brazos y piernas hallados en Jericó por Garstang en las excavaciones de los años treinta. Se documentó entonces la presencia de dos depósitos con sendos grupos de estatuas de tamaño casi natural que, en cada caso, se componían de un hombre, una mujer y un niño (Garfinkel, 1994, 163). Uno de estos grupos encontrado en una habitación estaba modelado en arcilla sobre una armadura de juncos. Igualmente, había bustos más esquemáticos. Y. Garfinkel (1994) señala también la existencia una cabeza de arcilla de idéntica procedencia y de otro fragmento hallado veinte años después (Figura 4, 1).

Por otra parte, en Tell Ramad se halló un personaje sentado, cuyo busto era un cilindro, probablemente un soporte para cráneo humano de los que se han hallado varios ejemplares en el mismo escondrijo, consistentes en estatuitas de arcilla recubiertas de una capa de materia blanca que han podido servir para este fin (Figura 4, 710). Y. Garfinkel (1994, 162), en cambio, es de la opinión de que dicha estatuilla podía tener una cabeza cilíndrica simplemente. Otro caso más es el de Nahal Hemar, donde también se halló una estatua humana de barro con los ojos pintados, así como fragmentos de otras estatuas antropomorfas (Garfinkel, 1994, 170-171).

En definitiva, se trata de una etapa de grandes cambios. A partir del 7600 cal.BC aumenta la circulación de productos a larga distancia seguramente por los corredores levantino y del Éufrates (obsidiana, recipientes y brazaletes de piedra y desde finales del periodo, 7000 cal.BC, las primeras cerámicas), planteándose también por ello la existencia de artesanos especializados (Aurenche y Kozlowski, 1999, 91-93). En el denominado PPNC en Levante sur, hay una multiplicación de las inhumaciones secundarias en las que los cráneos no se separan del cuerpo ('Ain Ghazal, por ejemplo). A pesar de la escasez de datos existente prácticamente en todas las áreas, es posible constatar aún una diversidad de tratamiento en los enterramientos y la desaparición definitiva del culto al cráneo, sea cual sea su significado. 


\section{LA INTERPRETACIÓN DE LOS DATOS}

K. Kenyon sugirió en su momento que los cráneos respondían a un culto a los antepasados, lo que ha sido recogido por otros investigadores más recientemente (Bienert, 1995, 79). En cambio, habida cuenta que se hallaron los de hombres, mujeres y niños, H. de Contenson (1992, 188) se inclinaba por considerarlos ritos de fundación. Y. Garfinkel (1994, 167) por su parte suponía que los cráneos podían ser testimonios de un culto a los antepasados, pero también de cultos a la fertilidad o retratos realizados como un tributo, elegidos por la forma. Del mismo modo, opinaba que los hallados en grupo pueden responder a la presencia de varias generaciones (Garfinkel, 1994, 170).

Para J. Cauvin, J.L. Huot (1994, 46-47) y J.D. Forest podrían pertenecer a los jefes de la familia, adquiriendo una perspectiva genealógica que, en las épocas históricas, llega a sus últimas consecuencias con las familias reales sumerias. Otros autores eran de una opinión más matizada. Según Forest, no es probable que se tratase de los antepasados en general, ya que los cráneos constituyen sólo una minoría (Huot, 1994, 46-47). A ello añadiría yo que algunos cráneos modelados (muy escasos) suponen la intención de reproducir las facciones de la persona concreta, a diferencia de los del PPNA que aparecían sin modelar. El propósito del modelado pudo ser en ciertos casos, posiblemente, la reproducción de los rasgos del difunto mediante diversos recursos. Pero aún cuando estas particularidades no se dan puede que, respetando ciertos convencionalismos o costumbres rituales, se desee también representar a antepasados, directos o no. Esta intención de personalizar el objeto parece hallarse más en relación con lo sugerido por Forest. Ritos de esta índole se constatan en poblaciones actuales de las islas del Pacífico, siendo considerados signos de cariño por parte de las familias y un buen comportamiento filial la consecución de estos rituales. Bienert $(1995,82)$ opina igualmente que forman parte de un culto a los antepasados, pero que dado que sólo una parte de los difuntos recibió este tratamiento, cabe pensar en líderes o ancianos cuya cabeza representara a la persona (pars pro toto). Seguramente, mediante estos rituales se quisieron conservar los poderes espirituales de estos líderes muertos para pedirles consejo o ayuda.

Recientemente, M. Verhoeven (2002) ha estudiado el ritual y la ideología, de los grupos humanos del PPNB que habitaron Levante y el SE de Anatolia, proponiendo para ello cinco conceptos básicos, uno de los cuales es la analogía (Verhoeven, 2002, 235): "Finally, analogy is part of the model since it has been argued that it is only through analogical reasoning (in its widest sense, including the use of ethnographic "parallels") that we can comprehend the past." Esta afirmación, que podría entroncar con la necesidad expresada por L. Binford de conocer la parte estática y la parte dinámica de las culturas y que dio paso al enfoque etnoarqueológico, adolecería aquí de ese afán por hallar fundamentalmente paralelos, esto es, similitudes y no tanto posibilidades de interpretación que incluirían igualmente las diferencias. En su opinión, el ritual puede invadir todos los aspectos de la vida (Verhoeven, 2002, 236), teniendo muchos de ellos un carácter público, seguramente con el objeto de integrar a la comunidad, legitimando el orden social. Pero, el número de personas que cabe en los edificios encontrados no es muy elevado. Evidentemente, podrían existir también rituales domésticos. A su juicio, estos edificios tendrían una función semejante a los de los Iatmul (Nueva Guinea), donde se almacenan los objetos sagrados y donde se pueden celebrar reuniones y fiestas. En todo caso, parecen haber tenido lugar rituales diferentes en edificios diferentes (Verhoeven, 2002, 247248). La idea de que los cráneos se relacionaron con ceremonias o festivales comunitarios, en contraste con el ritual de enterramiento primario, es compartida por Kuijt y Goring-Morris (2002, 296).

Según M. Verhoeven (2002, 246), en relación con los cráneos, se darían varias posibilidades. Los esqueletos decapitados en áreas domésticas y en edificios rituales responderían a rituales funerarios domésticos y públicos, respectivamente, a un culto al cráneo y a ritos de paso. Los esqueletos decapitados en sitios especiales reflejarían rituales públicos funerarios, culto al cráneo, ritos de paso, fiestas y festivales. Los depósitos de cráneos en áreas domésticas y los cráneos modelados en áreas domésticas supondrían un culto al cráneo doméstico. Finalmente, los depósitos de cráneos en áreas rituales y los depósitos de cráneos en sitios especiales corresponderían a un culto al cráneo público. Tal como he indicado anteriormente, ¿cabría atribuir la práctica de uno u otro tipo de celebraciones según se tratase de progenitores o de personajes clave para el grupo?

Este autor (Verhoeven, 2002, 248) señala además que el marcado simbolismo ritual del PPNB fue una expresión del deseo de controlar el comportamiento ritual y el mundo sobrenatural a fin 
de controlar también el mundo de los seres humanos. Del mismo modo, la vitalidad estaría referida a la domesticación, fecundidad (fertilidad) y a la fuerza vital (poder vital que reside en la cabeza), lo que se vincularía a los cráneos. Por otra parte, algunos estudios parecen indicar que sólo los cráneos anormalmente anchos han sido modelados (deformación en vivo producida a una edad temprana) (Verhoeven, 2002, 249). De nuevo, dos ejemplos de sociedades vivas ilustrarían esta opinión. Los Naga de Pakistán creen que la fuerza vital reside en la cabeza y asegura el bienestar y la fecundidad, lo que se explicita en ciertos rituales (Verhoeven, 2002, 249-250). Los Iatmul (zona del río Sepik, Nueva Guinea) desarrollan sus ceremonias en la casa de los hombres donde hay cráneos modelados con barro de antepasados y enemigos, colgados o depositados en nichos. Los más importantes o los más hermosos están decorados con pinturas, conservando el pelo y utilizando conchas para simular los ojos. Son tanto masculinos como femeninos. Se usan en rituales de muerte, pero también de fertilidad (Verhoeven, 2002, 250). Supone M. Verhoeven que en el Próximo Oriente sólo los cráneos de personajes están modelados. En la mismas línea, las figuritas decapitadas halladas en 'Ain Ghazal', serían ritualmente muertas para dar vida. Si admitimos esta interpretación, cabría explicar de la misma forma los posibles sacrificios infantiles o la presencia de cráneos de niños. Nuevos hallazgos permiten también entrever complicados rituales en relación con determinadas especies animales (Verhoeven, 2002, 253).

La Etnoarqueología nos proporciona vías de interpretación en Prehistoria (no analogías aplicadas de forma mecánica e indiscriminada), que pueden señalar posibilidades de explicación no desarrolladas hasta el momento y, también en este caso, nos encontramos en grupos actuales con prácticas de significados diversos que incluyen la manipulación de cráneos y otros restos. Los Abelam de Nueva Guinea viven en las tierras altas cultivando el ñame y criando cerdos, costoso trabajo que les ha llevado a desarrollar complicados ritos y ceremonias sociales. Habitan en grandes poblados de entre 350 y 1000 habitantes y existen los Big Men, cuya autoridad se basa en el prestigio personal también difícil de mantener. Los rituales incluyen un culto al ñame.

5 En el citado yacimiento, se hallaron unas 150 figurillas de arcilla, de las cuales unas 40 eran humanas (sobre todo femeninas), algunas decapitadas y el resto de ani-
Desde la siembra, pasando por el crecimiento y hasta la recolección de este tubérculo deben observarse una serie de normas, ya que se cultiva en huertos especiales a los que sólo los hombres que las respetan tienen acceso. Los ritos mágicos encaminados a mejorar la calidad de la planta se practican en una pequeña choza situada dentro del huerto. Los cráneos de los antepasados, largas piedras (de carácter fálico en ocasiones), y tallas de madera que representan a los muertos constituyen los símbolos de la naturaleza y de los espíritus del clan, respectivamente. Recogido el ñame, los tubérculos más hermosos se engalanan con máscaras y otros adornos para asociarlos a los espíritus (Forge, 1990, 59-67).

En la isla de Malekula (Vanuatu), se practica igualmente un culto al cráneo o a los antepasados. Los primeros son modelados con barro y fibras de cocotero para que resulte lo más parecido a los rasgos del difunto. Los cráneos de los padres permanecen en las cabañas familiares. En ocasiones, conservan el pelo natural y están pintados. En algunas sociedades secretas, los cráneos se ponen en postes y se exhiben en determinadas ceremonias.

Los Mbotgote de Malekula son también cultivadores de tubérculos (taro y ñame) y criadores de cerdos. Por cierto, estas comunidades practican la deformación craneal desde el nacimiento. La creencia en los espíritus de los antepasados es vital para estos grupos, ya que la vida se conserva gracias a la confianza de los mismos y la fertilidad y la cooperación de los espíritus se consiguen mediante ritos y ceremonias que acompañan a cada funeral cuya grandeza dependerá del rango alcanzado por el difunto. No obstante, no hay un jefe y la autoridad es ejercida por los ancianos. Existe la sociedad nimangi, distinta para el hombre y para la mujer, dentro de la cual se puede alcanzar una posición más o menos destacada.

Los ritos de hombres y mujeres para conseguir una posición destacada son distintos y se practican por separado. En el caso de la sociedad femenina, el rango social se obtiene por la extracción del incisivo derecho, lo que se acompaña de danzas. En ellas, las iniciadas llevan el cráneo de algún pariente femenino muerto, cuyos rasgos se han reproducido en arcilla. Ello asegura que el espíritu de la difunta participará

males (el 90\% bóvidos que, en dos casos, tenían hojitas de sílex clavadas en el cuerpo). 
en la ceremonia y ayudará a los parientes vivos o, al menos, no les causará ningún mal. En algunas danzas, se lleva el cráneo sobre un pequeño pedazo de bambú, asistiendo así a la matanza de cerdos que tiene lugar después de la ceremonia.

En los complicados funerales masculinos, el cadáver se prepara para las ceremonias en la casa de los hombres, después se expone en una choza familiar (a veces durante un mes), excavando alrededor del cuerpo un canalillo de unos $15 \mathrm{~cm}$ al que van a parar los humores fisiológicos, a continuación el difunto se deposita en la choza funeraria y, coronando el poste más alto de la misma, se coloca el cráneo de un pariente muerto. Igualmente, máscaras antiguas conservadas en la casa del difunto, se sitúan sobre estacas frente a la choza funeraria, lo que asegura la participación de los antepasados en los funerales, junto con colmillos de cerdo para simbolizar la riqueza del difunto. Los asistentes danzan frente a ellas. Después de abundantes sacrificios de cerdos, los huesos del difunto se entierran en el suelo de la choza funeraria, pero no el cráneo. Éste pasa a formar parte de una estatua llamada rhambaramb, que se erige para agradar a los antepasados y cuyo origen se sitúa en un mito. Dichas estatuas se fabrican sobre una estructura de madera recubierta de arcilla rojiza y fibras de liana. Los brazos y las piernas son de bambú y el torso es un tronco de árbol. La cabeza naturalmente es el cráneo del difunto. Esta estatua se expone frente a la estructura funeraria y, detrás, en semicírculo hay pequeñas figuras con los brazos en alto, representando a los hijos del difunto y, más atrás aún, se dispone un pequeño muro de bambú, por cuya parte superior asoman máscaras colocadas detrás, con los ojos grandes y dilatados que simbolizan a otros espíritus. Una gran procesión de hombres lleva también máscaras cónicas, representado de nuevo a los espíritus. De esta forma, se describía parte del complicado ceremonial existente en los funerales de algunos individuos que, en algún caso, pudieron durar un año (Muller, 1990, 116-120).

En general, en las islas de Melanesia, las máscaras representan la presencia de los espíritus en los rituales funerarios y, en Nueva Irlanda por ejemplo, eran destruidas al terminar las ceremonias (Jorgensen, 1995, 99). En una palabra, a través de estos ritos se evidencia la cercanía de los parientes muertos al mundo de los vivos y la necesidad de asegurar su presencia en las ceremonias que garanticen, por un lado, una buena relación con ellos y, por otro y relacionado con lo anterior, asegurar la continuidad del grupo (fecundidad del cultivo y de los propios seres humanos). A ello habría que añadir, el respaldo para la adquisición de un status superior (confianza de los ancianos, presencia de los parientes en el ritual funerario...).

\section{A MOdo DE CONCLUSión}

En definitiva, desde los precedentes de la sociedad agrícola (Natufiense), se constatan rasgos que pervivirán durante milenios. Uno de ellos es la diversidad de ritos de enterramiento, determinada quizá por la movilidad del grupo, diversidad que, en este momento, incluye ya la decapitación del cadáver en algunos casos. Pero igualmente pueden señalarse otros elementos diferenciales (ver Cuadro 2), uno de los cuales podría darse entre el propio enterramiento y la exposición del cadáver, habida cuenta del número estimado para los habitantes de los poblados. Parece claro el deseo de retener en la proximidad de los vivos a algunos individuos al practicar el enterramiento bajo el suelo de las casas, indicando quizá que siguen formando parte de la familia o que ejercen un papel protector de la misma. Al mismo tiempo, se evidencia la posible idea del enterramiento familiar o clánico (tumbas colectivas). Todo parece girar pues en torno a la familia y a los vínculos de parentesco, en el seno de grupos más bien pequeños. La diferenciación apuntada por J. Mellaart podría producirse entre grupos de edad y sexo, pero igualmente para algún miembro destacado de la comunidad a causa de sus cualidades personales, tal como se constata en sociedades de cazadores-recolectores actuales.

En los inicios de la neolitización (PPNA), no parece haberse fijado el rito de enterramiento, lo que desde luego puede responder también a una movilidad variable (enterramientos secundarios) o a diferencias de identidad entre grupos, aunque son posibles otras interpretaciones. Ello concordaría con la ausencia de una economía de producción clara, defendida por $\mathrm{O}$. Aurenche y de M. Kozlowski (1999), aunque no puede descartarse que en este momento se estén practicando un cultivo y una domesticación sobre especies todavía silvestres y que, de forma paralela y por éste u otros motivos (desarrollo de intercambios comerciales, por ejemplo), algunos de los grupos estén generando ya otro tipo de organización social. A los hechos diferenciales antes observados se uniría el tratamiento de los cráneos. Algunos de ellos han debido pertenecer a los cuerpos decapitados enterrados principalmente 
bajo las casas. Cabe pensar que los depositados en basureros, junto con otros restos humanos, provendrían igualmente de enterramientos primarios, practicados quizá en un lugar distinto al poblado o sus cercanías. Los cráneos en general pudieron ser utilizados en ceremonias y desechados después, pero otras veces serían custodiados en las viviendas. No parece haber estado en el ánimo de quienes llevaron a cabo las celebraciones reproducir los rasgos de la persona en cuestión, algo en lo que abundaría la supresión de la mandíbula, sino rendir culto a la figura que representan (antepasado, progenitor, personaje destacado del poblado, etc.), o asegurarse su protección. $\mathrm{O}$ simplemente, se enmarcarían en la vertiente social del sepelio y su conmemoración posterior. De todos modos, la atención prestada ahora a algunos cráneos (efigies de los progenitores) podría estar relacionada con una organización social vinculada a la unidad doméstica, familiar, documentada en sociedades tribales de primeros agricultores. Pero también cabría pensar en signos de diferenciación social cuyo carácter habría que discutir. En ese sentido, sería coherente pensar que las diferencias antes apuntadas podrían estar relacionadas con grupos de edad y sexo al igual que en momentos anteriores. No obstante, ejemplos como el de Tell Mureybet III apuntan seguramente a distinciones vinculadas al status o, más probablemente, a la especialización religiosa. Casos aislados como los cráneos depositados en hogares-cubeta o en basureros carecen por el momento de explicación adecuada, aunque puede tratarse de los utilizados en celebraciones y desechados después.

Durante el PPNB se afianzan ciertas pautas establecidas y se multiplica la diversidad. Los enterramientos de individuos jóvenes o niños parecen ser predominantes en los relacionados con las viviendas. Con todo, hasta alcanzar una edad, temprana, son arrojados a los basureros, caso que se extiende también a algunos adultos sin decapitar. Estos hallazgos resultan significativos por lo que respecta a su posición en la sociedad o en la familia (niños muertos a corta edad o en el momento de su nacimiento). Podría sugerirse que una ausencia de identidad a causa de su poca edad o de la falta de ritos de paso aún no celebrados a causa de una muerte tan temprana habría ocasionado esta aparente discriminación en el enterramiento. La de los adultos en idéntica situación se debería sin duda a otros motivos, pero su posición posiblemente inferior se refuerza por la conservación de los cráneos junto con el resto del esqueleto que, a diferencia de los de otros miembros del grupo, no se exponen en distintos lugares. ¿Cabría pensar en individuos sin descendencia?

La ubicación de los enterramientos es también variada, destacando los hallados bajo los santuarios, tampoco numerosos, que denotarían la singularidad de los inhumados. Podrían ser éstos personas relacionadas con el mundo de la religiosidad, como en el momento anterior. Es significativo en este sentido el yacimiento de Çatal Hüyük, donde tales individuos, presentan un ajuar que denota seguramente un status más elevado. En mi opinión, de todos modos aún plasmando una diferenciación, en el yacimiento anatolio se quiere reproducir el patrón habitual, ya que el santuario presenta la misma estructura que la casa. Esta vinculación con la vivienda, en el caso de los adultos, podría quizá indicar su condición de padres y madres de familia.

En el PPNB, no todos los cráneos se decoran, hallándose también cuerpos decapitados, como en el periodo anterior. Sin embargo, hay diferencias evidentes, siendo quizá la más destacada el modelado de los cráneos en Levante sur. Éste pudo obedecer, bien al deseo de reproducir los rasgos del difunto en raras ocasiones (¿progenitores?), bien al respeto por ciertos convencionalismos, expresados igualmente en las estatuas modeladas, a la hora de representar personajes destacados (antepasados míticos de los grupos de filiación, individuos cabeza de dichos grupos, líderes de diversa condición, etc.), objeto de culto. Por otra parte, los cráneos corresponden a individuos de distinto sexo y edad. En el caso de los adultos, la presencia femenina estaría relacionada con la figura materna, ya que en sociedades tribales la mujer raramente ostenta ninguna autoridad y tampoco suele ser el antepasado apical de los grupos de filiación. La presencia de cráneos infantiles podría estar vinculada a la delimitación de estos grupos o de familias más destacadas. Sin embargo, los niños decapitados enterrados con adultos que conservan el cráneo resulta más difícil de interpretar, ya que suponen una aparente contradicción con la sugerencia anterior.

Si se comprobara la función de estatuillas como las de Tell Ramad, se afirmaría la idea de la conservación y exposición de algunos cráneos en la vivienda (lo que vendría reforzado por el hallazgo de algunos sobre montones de arcilla), o en otro tipo de edificios, algo que a mi juicio, mostraría las diferencias existentes entre las diversas áreas, pero también en el seno de cada grupo: cráneos sin modelar fuera de Levante, cráneos modelados en Levante, cráneos que 
reproducen rasgos, cráneos sujetos a un modelado semejante a la estatuaria, cráneos aislados, en depósitos, en las viviendas y en edificios "especiales". En mi opinión, los primeros, sin modelar, representarían la expansión del ritual, pero no del conjunto de las creencias. Los segundos, modelados, constituirían las efigies de personas más cercanas (padres), supuestamente vinculadas a las viviendas, en el caso de los que reproducen rasgos del individuo y serían objeto de un culto doméstico. Los modelados de forma semejante a las estatuas reproducirían los personajes señalados más arriba. De éstos, los cráneos hallados en edificios "especiales" podrían formar parte de celebraciones colectivas. Lo mismo sucedería con los encontrados en depósitos sagrados. Por último, los aislados, redepositados en la sepultura o depositados con otros restos, incluso en basureros, supondrían el destino final de los cráneos a la conclusión de los rituales.

Deben explicarse adecuadamente las máscaras, que suponen una novedad, si bien no son en absoluto abundantes. Bienert $(1995,81)$ señala que, dado el tamaño de las mismas, no servirían para ser usadas por los vivos, sino que sustituirían a la cara en los cráneos decorados, como se ha defendido para las de 'Ain Ghazal, yacimiento que presenta un marcado carácter ritual. También la cueva de Nahal Hemar ha sido interpretada como un lugar sagrado. ¿Sería descabellado suponer la celebración en ella de ciertos ritos que implicaran la utilización de los citados objetos?

Dada la diversa situación de los hallazgos de cráneos, parece que podría suponerse su uso en rituales tanto domésticos como colectivos, como defiende Verhoeven. Los rituales colectivos reforzarían la cohesión entre los miembros de la comunidad y los domésticos supondrían el cumplimiento de unas obligaciones rituales para con los progenitores. No estoy de acuerdo, en cambio, con este autor en su explicación de que la fuerza vital radique en la cabeza. En mi opinión, no se trata tanto de expresar esa idea como de señalar la propia presencia de los espíritus de parientes concretos o antepasados. Si creo, en cambio, que puede haber diferencias entre las personas cuyos cráneos se utilizan en los rituales y el resto de la comunidad. El hallazgo de cráneos infantiles reforzaría esta idea, como ya he señalado. No obstante, aunque no puede excluirse la diversidad de rango, la existencia de las referidas diferencias en el seno del grupo no implica la presencia de una autoridad central permanente. En cualquier caso, parece claro que los lazos de parentesco continúan vigentes. Pero muy probablemente se perfilan ya distintos grupos de filiación, característicos de la sociedad tribal.

La aparición de restos bajo el umbral o los muros de las casas podrían corresponder a ritos de fundación o quizá a una función protectora ejercida por esos miembros de la familia aún presentes de ese modo. La vinculación de los difuntos a la casa creo que no puede explicarse más que con un sentido de protección o como refuerzo de la idea de familia. Sin embargo, la propiciación de la fertilidad que defiende Verhoeven formaría parte, a mi modo de ver, de esa protección más general que se solicita al antepasado (o progenitor) protector de la familia y del grupo.

En el PPNB nos encontramos, desde luego, ante un mundo simbólico cada vez más complejo. Podría sugerirse que nos hallamos en un momento de transición a otro tipo de sociedad y al desarrollo de una nueva forma de pensamiento religioso. En ésta (e incluso en el PPNA anterior), determinados animales parecen jugar un importante papel, vinculándose claramente a los seres humanos (caso de Kfar Hahoresh, enterramiento de un ave rapaz, importancia de los bucráneos y cráneos de ciertas especies animales). ¿Podría sugerirse la creencia en un animal mítico ancestral que marcara, una vez más la diferencia entre grupos de filiación? Todo ello estaría vinculado a la existencia de una economía de producción clara, a una movilidad definitivamente más reducida, posiblemente a grupos de mayor tamaño y también al desarrollo de la artesanía y el comercio. Por desgracia, el problema con que nos hallamos es el desequilibrio entre los testimonios procedentes de cada región.

Con la aparición y desarrollo de la cerámica, uno más de los cambios tecnológicos, desaparecen las prácticas relacionadas con los cráneos, aún cuando se mantengan ciertos enterramientos bajo el suelo de las casas. Sin embargo, parece haber una proliferación de los cementerios fuera del poblado, lo mismo que de las tumbas individuales y el predominio del enterramiento primario. El individuo podría ostentar ahora la posición social (con excepciones), expresada en el mundo funerario y en otros aspectos. Así, frente a un sentido más colectivo en la economía se pasaría, en algunos casos, a otro de apropiación individual como demostraría la presencia de sellos (marcas de propietario), rasgo que no obstante se atestiguaba ya en algunos grupos anteriores. En todo caso, los hallazgos de cráneos que estudiamos se centran para los tres periodos en Levante sur, y escasamente en la Yazira y en 
Anatolia en el tercer momento, lo que parecería responder a la máxima expansión de la idea (ċa través del comercio a larga distancia?), inmediatamente anterior a su desaparición total.

\section{Bibliografía:}

AURENCHE, O. Y KOZLOWSKI, S.K. (1999): La naissance du Néolithique au Proche Orient ou le paradis perdu. París.

BAR-YOSEF, O. y ALON, D. (1992): "Nahal Hemar Cave". Antiqot junio, 1-81.

BIENERT, H.-D. (1995): The human image in the Natufian and Aceramic Neolithic Period of the Middle East. WALDREN, W.H., ENSENYAT, J.A. y KENNARD, R.C. (Eds.): Rituel, rites and religions in Prehistory. IIId Deyà International Conference of Prehistory, 1. B.A.R. International Series 611.

BONOGOFSKY, M. (2001): "Cranial Modeling and Neolithic Bone Modification at 'Ain Ghazal: New Interpretations". Paléorient 27/2, 141-146.

CAMPBELL, S. (1995): 5. Death for the Living in the late Neolithic in north Mesopotamia. CAMPBELL, S. y GREEN, A. (Eds.): The Archaeology of death in the Ancient Near East. Oxford Monograph 51.

CAUVIN, J. (1994): Naissance des divinités. Naissance de l'agriculture. París.

(2000): The birth of the gods and the origins of agriculture. Cambridge University Press. Postscript, 213-222 (traducción de T. Watkins).

(2001): Comentarios a la traducción inglesa (J. Cauvin, I. Hodder, G.O. Rollefson, O. Bar-Yosef y respuesta de T. Watkins). Review Feature. Cambridge Archaeological Journal 11. 1, 105-121.

CONTENSON, H. DE (1992): "Les coutumes funéraires dans le Néolithique syrien". Bulletin de la Societé Préhistorique Française 98/6, 184-191.

FORGE, , A. (1990): Los Abelam. Nueva Guinea. Pueblos de la tierra: Australia y Melanesia, 59-67.

GARFINKEL, Y. (1994): "Ritual Burial of Cultic Objects: The Earliest Evidence”. Cambridge Archaeological Journal 4:2, 159-188.

GOREN, Y., GORING-MORRIS, A.N. Y SEGAL, I. (2001): "The Technology of Skull Modeling in the PrePottery Neolithic B (PPNB): Regional Variability, the relation of Technology and Iconography and their Archaeological Implications". Journal of Archaeological Science 28, 671-690.

HERSHKOVITZ, I. ET ALII (1995): "Remedy for an 8500 Year-old Plastered Human Skull from Kfar Hahoresh, Israel". Journal of Archaeological Science 22, 779-788.
HODDER, I. (1990): The Domestication of Europe. Structures and Contingencies in Neolithic Societies. Oxford.

JORGENSEN, D. (1995): Una diversidad de islas y culturas. BURENHUlT, G. (Ed.): Pueblos del Pacífico en el mundo moderno. Atlas culturales de la humanidad, 98109.

KINGERY, W.D., VANDIVER, P.B. y PRICKETT, M. (1988): "The Beginnings of Pyrotechnology, Part II: Production and Use of Lime and Gypsum Plaster in the Pre-Pottery Neolithic Near East". Journal of World Archaeology 15. 2, 219-244.

KUIJT, I. (ED.) (2000): Life in Neolithic Farming Communities. Social Organization, Identity, and Differentiation. Nueva York.

GORING-MORRIS, N. (2002): "Foraging, Farming, and Social Complexity in the Pre-Pottery Neolithic of the Southern Levant: A Review and Synthesis". Journal of World Prehistory 16.4, 361-440

MARGUERON, J.C. (1996): Los mesopotámicos. Madrid.

MELlAART, J. (1975): The Neolithic of the Near East.

(1994): Western Asia during the Neolithic and the Chalcolithic (about 12000-5000 years ago). LAET, S. de (Ed.): Prehistory and the Beginnings of Civilization, History of Humanity I, 425-440.

MOLIST, M. (1992): El origen y desarrollo del Neolítico en la zona del Próximo Oriente. Manual de Prehistoria Universal. 1: Prehistoria, 231-276. Madrid.

MULLER, K. (1990): Los Mbotgote de la isla MalekulaVanuatu. Pueblos de la tierra: Australia y Melanesia, 116120.

PARDO, P. (1999): Los primeros testimonios de la complejidad social en el Próximo Oriente. Memoria de Licenciatura inédita. U.A.M.

PUEBLOS DE LA TIERRA. Australia y Melanesia (1990). Barcelona.

REDMAN, CH.L. (1990): Los orígenes de la civilización. Barcelona.

ROLLEFSON, G.O. (1989): "The Aceramic Neolithic of the Southern Levant: the view from "Ain Ghazal". Paléorient 15.1, 135-139.

(1998): "'Ain Ghazal (Jordan): ritual and ceremony III". Paléorient 24.1, 43-58.

RUBIO, I. (E.P.): "El mundo funerario en el Próximo Oriente. Del Neolítico a la Revolución Urbana". I Jueves de Didáctica Oriental (Curso 1999-2000). La muerte y el más allá en Oriente Próximo. Centro Superior de Estudios de Asiriología y Egiptología. U.A.M.

SAÑA, M. (1999): Arqueología de la domesticación animal. La gestión de los recursos animales en Tell Halula (Valle del Éufrates-Siria) del 8.800 al 7.000 PB. U.A.B. 
SCHIRMER, W. (1990): "Some aspects of building at the "aceramic neolithic" settlement of Çayönü Tepesi". World Archaeology 21, 363-387.

SCHMANDT-BESSERAT, D. (1978): "El primer antecedente de la escritura”. Investigación y Ciencia agosto, 6-16.

STORDEUR, D. ET ALII (2001): "Les bâtiments communautaires de Jerf el Ahmar et Mureybet horizon PPNA (Syrie)", Paléorient, 26 (1), 29-44.

VALLA, F.R. (1975-1977): "La sépulture H104 de
Mallaha (Eynan) et le problème de la domestication du chien en Palestine". Paléorient 3, 287-292.

(19959: The first settled societies-Natufian (12,500-10,200 BP). VV.AA.: The Archaeology of Society in the Holy Land. Leicester University Press, 169-187.

VERHOEVEN, M. (2002): "Ritual and Ideology in the Pre-Pottery Neolithic B of the Levant and Southeast Anatolia”. Man XLVII, 233-258.

VV.AA. (1995): The Archaeology of Society in the Holy Land. Leicester University Press.

\section{CUADRO 1.- CRONOLÓGICO DE LAS CULTURAS EPIPALEOLÍTICAS, MESOLÍTICAS Y PRECERÁMICAS DEL PRÓXIMO ORIENTE. DATACIONES DE C14}

\begin{tabular}{|c|c|c|c|}
\hline & a.C. & a.C. & cal.BC $* * *$ \\
\hline $\begin{array}{l}\text { - PERIODO O: } \\
\text { Kebariense (Levante)/ } \\
\text { Zarziense ( Zagros) }\end{array}$ & 14000 & 17050 & \\
\hline $\begin{array}{l}\text { - PERIODO 1: } \\
\text { Natufiense (Levante)/ } \\
\text { Zarziense final (Zagros) }\end{array}$ & 10000 & 10800 & 12000 \\
\hline $\begin{array}{l}\text { PERIODO 2: } \\
\text { Protoneolítico (Siria- } \\
\text { Palestina)/PPNA (Jericó) }\end{array}$ & 8300 & 9050 & 10300 \\
\hline $\begin{array}{l}\text { - PERIODO 2: } \\
\text { PPNB (Siria Palestina)/ } \\
\text { Hacilar precerámico } \\
\text { (Anatolia)/fase Bush Mordesh (Zagros) }\end{array}$ & 7600 & 8550 & 8800 \\
\hline 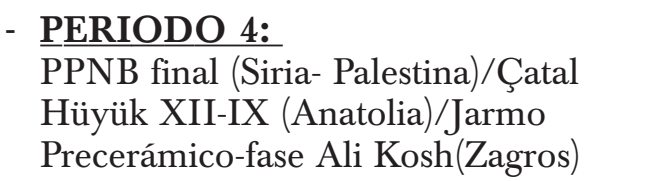 & 6600 & 7300 & 7600 \\
\hline
\end{tabular}

* Cronologías a.C. calculadas según la vida media "corta" (Libby) no calibradas (Escuela de Lyon)(Margueron, 1996, 61).

** Cronologías a.C. calculadas a partir de las BP ofrecidas por Mellaart (1994, 425).

** Cronologías cal.BC (ASPRO, Escuela de Lyon)(Aurenche y Kozlowski, 1999). 
CUADRO 2.- RESUMEN DE ALGUNAS DE LAS CARACTERÍSTICAS MÁS DESTACADAS DE LOS YACIMIENTOS DEL NATUFIENSE, PPNA Y PPNB, DETERMINADAS EN LA DOCUMENTACIÓN ARQUEOLÓGICA (1: JERF EL AHMAR, 2: GRILL PLAN Y CELL PLAN, 3: MÁS FRECUENTES Y 4: MENOS FRECUENTES).

\begin{tabular}{|c|c|c|c|}
\hline CARACTERÍSTICAS & Natufiense & PPNA & PPNB \\
\hline $\begin{array}{l}\text { ECONOMÍA } \\
\text { Caza y recolección } \\
\text { Agricultura y pastoreo }\end{array}$ & $\begin{array}{l}* \\
*\end{array}$ & $\begin{array}{l}* \\
*\end{array}$ & $\begin{array}{l}* \\
*\end{array}$ \\
\hline $\begin{array}{l}\text { ASENTAMIENTOS } \\
\text { Estacionales } \\
\text { Semisedentarios } \\
\text { Sedentarios } \\
\text { Cuevas } \\
\text { Gran tamaño } \\
\text { Menor tamaño } \\
\text { Muralla o Muro de contención } \\
\text { Torre } \\
\text { Bastiones } \\
\text { Santuarios } \\
\text { Plazas }\end{array}$ & $\begin{array}{l}* \\
* \\
* \\
* \\
*\end{array}$ & $\begin{array}{c}* \\
* \\
* \\
\text { Jericó } \\
\text { Jericó } \\
\\
*\end{array}$ & $\begin{array}{c}* \\
* \\
* \\
* \\
* \\
\text { Mazgalia } \\
* \\
*\end{array}$ \\
\hline $\begin{array}{l}\text { ESTRUCTURAS (HABITAT/SANTUARIOS) } \\
\text { Planta circular } \\
\text { Planta cuadrada o rectangular } \\
\text { Silos } \\
\text { Almacenes } \\
\text { Pinturas }\end{array}$ & * & $\begin{array}{l}* 1 \\
* \\
*\end{array}$ & $\begin{array}{c}* 2 \\
* \\
*\end{array}$ \\
\hline $\begin{array}{l}\text { ENTERRAMIENTO } \\
\text { Individual } \\
\text { Colectivo } \\
\text { Primario } \\
\text { Secundario } \\
\text { Cuevas } \\
\text { Bajo casas (abandonadas o no o patios) } \\
\text { Edificios rituales } \\
\text { Necrópolis } \\
\text { Silos } \\
\text { Basureros }\end{array}$ & $\begin{array}{c}* \\
* 4 \\
* \\
* \\
* \\
* \\
\\
*\end{array}$ & $\begin{array}{c}* 3 \\
* \\
* \\
* \\
\\
* \\
* \\
* \\
*\end{array}$ & $\begin{array}{l}* 3 \\
* \\
* \\
* \\
\\
* \\
* \\
* \\
* \\
*\end{array}$ \\
\hline $\begin{array}{l}\text { OTROS ELEMENTOS } \\
\text { Fichas (tokens) } \\
\text { Sellos }\end{array}$ & & & $\begin{array}{l}* \\
*\end{array}$ \\
\hline
\end{tabular}


CUADRO 3.- HALLAZGOS DE CRÁNEOS DEL NATUFIENSE Y PPNA

\section{NATUFIENSE}

Wadi Hammeh 27: Fragmentos de cráneos quemados (Valla, 1995, 176).

'Ain Mallaha (Israel): Cráneo que conserva dos vértebras con señales de cortes, hallado sobre el suelo de la Habitación I cerca de un hogar, y calota cortada encontrada sobre un suelo próximo (Valla, 1995, 176).

Hayonim (Israel): Esqueletos sin cráneo.

Nahal Oren (Israel): Esqueletos sin cráneo (Bienert, 1995, 76-77).

\section{PPNA}

Jericó (Palestina): Depósitos encontrados por K. Kenyon: nueve cráneos dispuestos en tres filas de tres, con la cara orientada al oeste; ocho cráneos (tres de adultos y tres de jóvenes) colocados en círculo mirando hacia el centro, depositados todos directamente sobre un nivel lleno de restos humanos mal conservados; un supuesto rito de fundación, con cinco cráneos infantiles, algunos con las vértebras, y el cuerpo de un niño en posición fetal, agrupados bajo una cubeta enlucida con la base de piedra, considerada como un altar. Otro supuesto rito de fundación estaba constituido por un niño depositado bajo el calce de piedra del soporte del techo de una habitación.

Mureybet (Siria): Sobre el suelo de la vivienda de la casa XXII, en tres casos, hay cráneos en las esquinas de las habitaciones, cubiertos con desechos y arcilla roja.

Jerf el Ahmar (Siria): Tres cráneos en la parte superior de un hogar-cubeta.

Quermez Dere (Iraq): Cuatro cráneos.

\section{CUADRO 4.- HALLAZGOS DE CRÁNEOS DEL PPNB RELACIONADOS CON ENTERRAMIENTOS}

'Ain Ghazal (Jordania): Enterramientos practicados bajo casas y patios, con los cuerpos decapitados y flexionados; en patios, con los cuerpos no flexionados y con cráneo, e infantiles (Verhoeven, 2002, 237). Restos de niños menores de quince meses bajo las puertas, como depósitos en los cimientos (ćritos de fundación?) o en contextos ceremoniales, como fosas con cráneos recubiertos de yeso. La mayoría de los infantiles estaban asociados a desechos y aparecían sin decapitar. En el PPNB medio de este mismo yacimiento, adultos y también adolescentes se hallan en basureros con el mismo tratamiento que los cráneos.

Basta (Jordania): Inhumaciones bajo el suelo de las casas, a veces sin el cráneo, después redepositado.

Beidha (Jordania): Cuarenta y tres enterramientos (diez de adultos y treinta y tres de niños) bajo el suelo de las viviendas. Los adultos se enterraban después de ser decapitados, salvo algunas excepciones.

Jericó (Palestina): Treinta individuos hallados, algunos intactos y otros decapitados, seguramente después de la descomposición del cadáver, depositados sobre un lado. Un supuesto sacrificio infantil depositado en un receptáculo de yeso y barro bajo un hábitat. Al lado otro enterramiento de un niño con las vértebras del cuello rotas y la cabeza cortada. Se enterraba en el área de habitación, planteándose la posible destrucción de la casa después del enterramiento. Asimismo, se encontraron esqueletos y cráneos en la escalera de la torre que entonces había perdido ya su función.

Abu Gosh (Israel): Sepulturas primarias individuales a veces sin cráneo. 
Tell Ramad (Siria): Doce cráneos modelados y pintados en una cavidad oval rodeada de adobes bajo la casa 10 (Nivel II), cerca de los enterramientos de los niños. Estaban divididos en pequeños grupos, separados por pellas de arcilla, enlucida y pintada.

Tell Aswad (Siria): En el nivel IIB, en una fosa colectiva, un esqueleto de adulto descansaba sobre el costado derecho, con el brazo derecho sobre un cráneo, un esqueleto de un niño en conexión y otro sin ella, un cráneo de adulto con la mandíbula depositada cerca y varios cráneos y restos humanos en desorden. En otra zona apareció un cráneo aislado sin mandíbula (Contenson, 1992, 186).

Dja'de (Siria): Construcción de tres pequeñas habitaciones con una cuarentena de esqueletos y de cráneos aislados (inhumación primaria), de los cuales dos se hallaban bajo la solera de la construcción. Se ha denominado la "Casa de los muertos" y en ella todos los enterrados son niños y adultos jóvenes que presentan un tratamiento variado. Aparecen además una serie de cráneos, pero el grupo más espectacular estaba compuesto por restos de trece individuos hallados sobre el suelo de una estancia rectangular (un adulto aparecía en posición semiflexionada, teniendo contra él a un joven cuya mano descansaba sobre un cráneo); en otro caso se documentaron restos de tres individuos, alineados en un estante con piedras y guijarros y, cerca, otro enterramiento de unos treinta y ocho individuos con el esqueleto completo.

\section{CUADRO 5.- HALLAZGOS DE CRÁNEOS DEL PPNB AISLADOS O EN DEPÓSITOS}

'Ain Ghazal (Jordania): Doce cráneos de adultos (parece que todos masculinos) y niños, uno de ellos en el suelo de una casa y en silos bajo el suelo de las casas o patios el resto. Tres cráneos modelados se hallaban dispuestos en hilera mirando al exterior (Kuijt y Goring-Morris, 2002, 395).

Basta (Jordania): Cráneos aislados.

Jericó (Palestina): El hallazgo bajo el suelo de una casa de dos cadáveres de niños con las piernas flexionadas se interpretó como un rito de fundación (Contenson, 1992, 188)( las tumbas infantiles son más raras). Una casa con dos cráneos de jóvenes o femeninos en una pequeña fosa rectangular y una sepultura de una mujer de unos veinte años, en posición contraida, con una punta de sílex, se ha interpretado como un santuario. Tres cráneos aislados aparecieron en otros lugares. Nueve cráneos modelados o pintados se hallaron en dos grupos de siete y dos (probable desplazamiento de los restos). Uno modelado apareció aislado. En total, doce (cinco de ellos con pintura) están modelados y otros dos presentan restos de pintura (en la parte superior para simular el pelo y bajo la nariz para dibujar el bigote en un caso). En los ojos había plaquetas de nácar y en uno femenino cauríes. De los citados, diez eran femeninos, tres masculinos y uno indeterminado (Contenson, 1992, 188-189) (Figura 3C, 1-3). La compleja estratigrafía no permite saber si los 10 o 12 hallados por K. Kenyon se hallan realmente en lugares de habitación o en enterramientos (Bienert, 1995, 78).

Kfar Hahoresh (Israel): Bajo el suelo de una estructura rectangular apareció un cráneo enlucido pintado en rojo bien conservado junto al cuerpo de una gacela prácticamente completo pero sin cabeza. Otros huesos humanos, incluyendo cráneos, se asociaban a una variedad de restos de uro y gacela. En un profundo y gran silo relleno de ceniza se hallaron restos humanos (al menos de 4 individuos) y de gacela que vistos desde arriba diseñaban el perfil de un animal (jabalí, uro o quizás un león)(Verhoeven, 238).

Nahal Hemar (Israel): Seis cráneos humanos decorados con asfalto con un patrón de red o modelados en arcilla (también un tocado con un patrón similar), junto con dos máscaras de arcilla pintadas y de piedra (Figura 4, 2).

Beisamoun (Israel): Dos cráneos femeninos modelados encontrados a la entrada de una de las casas con enlucido en el suelo (Contenson, 1992, 186)(Figura 3C, 4).

Tell Ramad (Siria): Cuatro o cinco cráneos (Figura 4, 3, 5 y 6).

Mureybet IVB (Siria): Cráneos depositados sobre un montón de tierra o sobre una figura. Cinco cráneos modelados se alineaban sobre el suelo de una casa a lo largo de un muro y con montones de arcilla roja como pedestales (Contenson, 1992, 186). Otros dos con la misma disposición aparecieron enterrados. 
Tell Abu Hureyra (Siria): Depósitos de cráneos (sólo o en grupos de cráneos y esqueletos) en fosas poco profundas dentro de las casas o en el interior de los patios.

Tell Halula (Siria): Cráneos sin mandíbula.

Bouqras (Siria): La denominada "Casa quemada" ( $\left.n^{\circ} 12\right)$ contenía enterramientos individuales que, en algún caso, se reducían a un cráneo infantil y, en otros, a restos de cráneos dañados, distribuidos por las habitaciones.

Nevali Çori (Turquía): Enterramientos de cráneos reagrupados bajo el suelo de las casas (Verhoeven, 2002, 238-239).

Çayönü (Turquía): En uno de los edificios rituales denominado "de los cráneos" (Skull-building)(Figura $3, \mathrm{~B})$, reconstruido varias veces, se depositaron cráneos humanos (setenta y seis cráneos aislados de mujeres, hombres y niños, pero sobre todo de adultos jóvenes, algunos sin mandíbula) sobre el suelo original y en dos silos centenares de esqueletos humanos (entre trescientos y cuatrocientos), en un caso con cráneos de uro y cuernos. En las últimas fases, en pequeñas celdas, se hallaron cráneos y otros huesos humanos. En las habitaciones, un total de 49 cráneos humanos quemados parecían haber caído de estantes. De los restos hallados, se deduce la presencia de al menos 450 individuos (Verhoeven, 2002, 239-240).

Kösk Höyük (Turquía): Un cráneo modelado y coloreado con ocre de una mujer de entre 16 y 25 años, de atribución dudosa a causa de la estratigrafía (Garfinkel, 1994, 165 y Bienert, 1995, 80).

Hacilar Turquía): Cráneos humanos en las esquinas de los hogares o en los patios.

Nemrik (Iraq): Cráneos depositados en las casas 1 y 2.

Qermez Dere (Iraq): Cráneos en una casa abandonada.

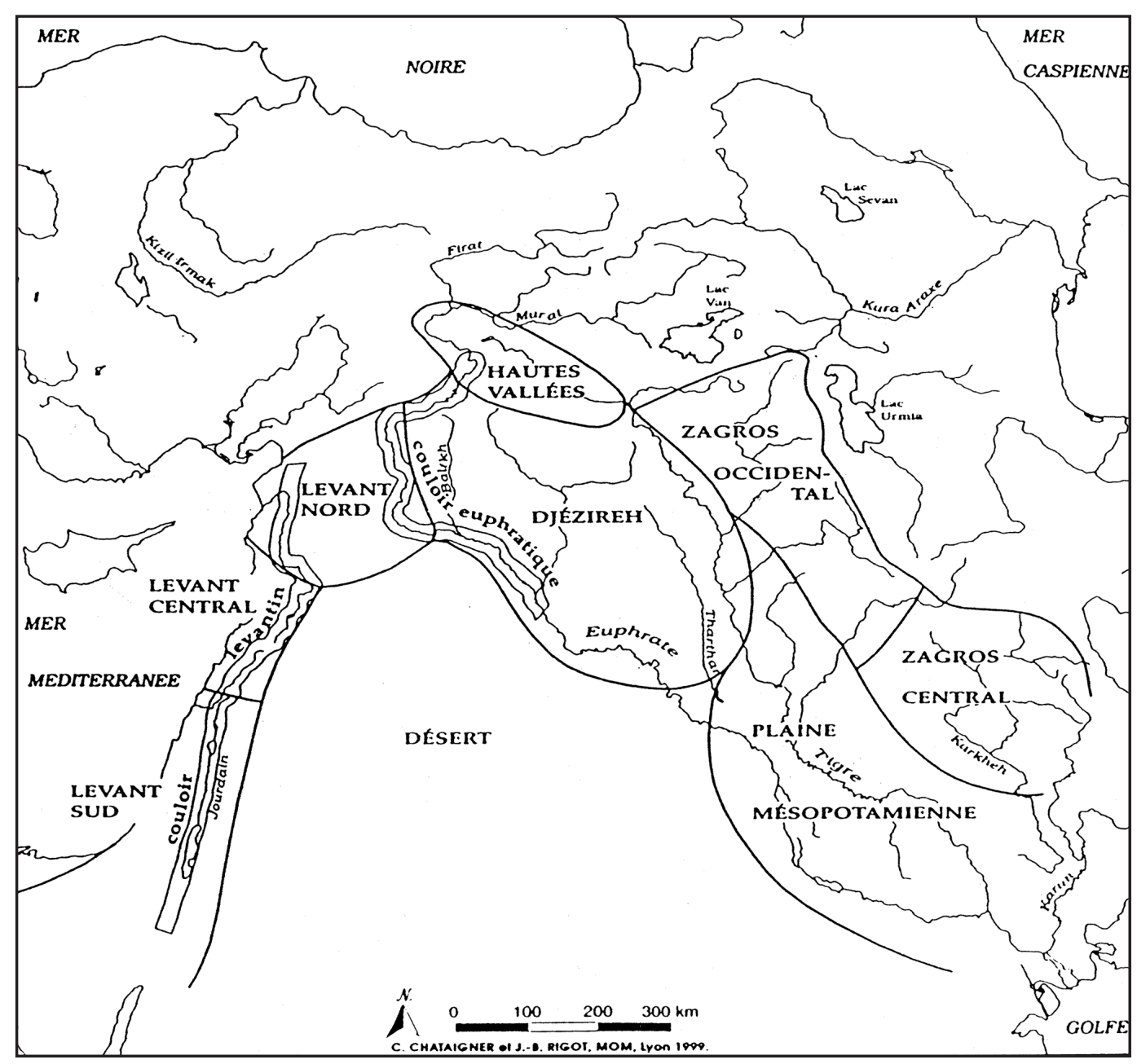

Figura 1.- Mapa de las grandes zonas geo-culturales del Próximo Oriente (Aurenche y Kozlowski, 1999, 4). 


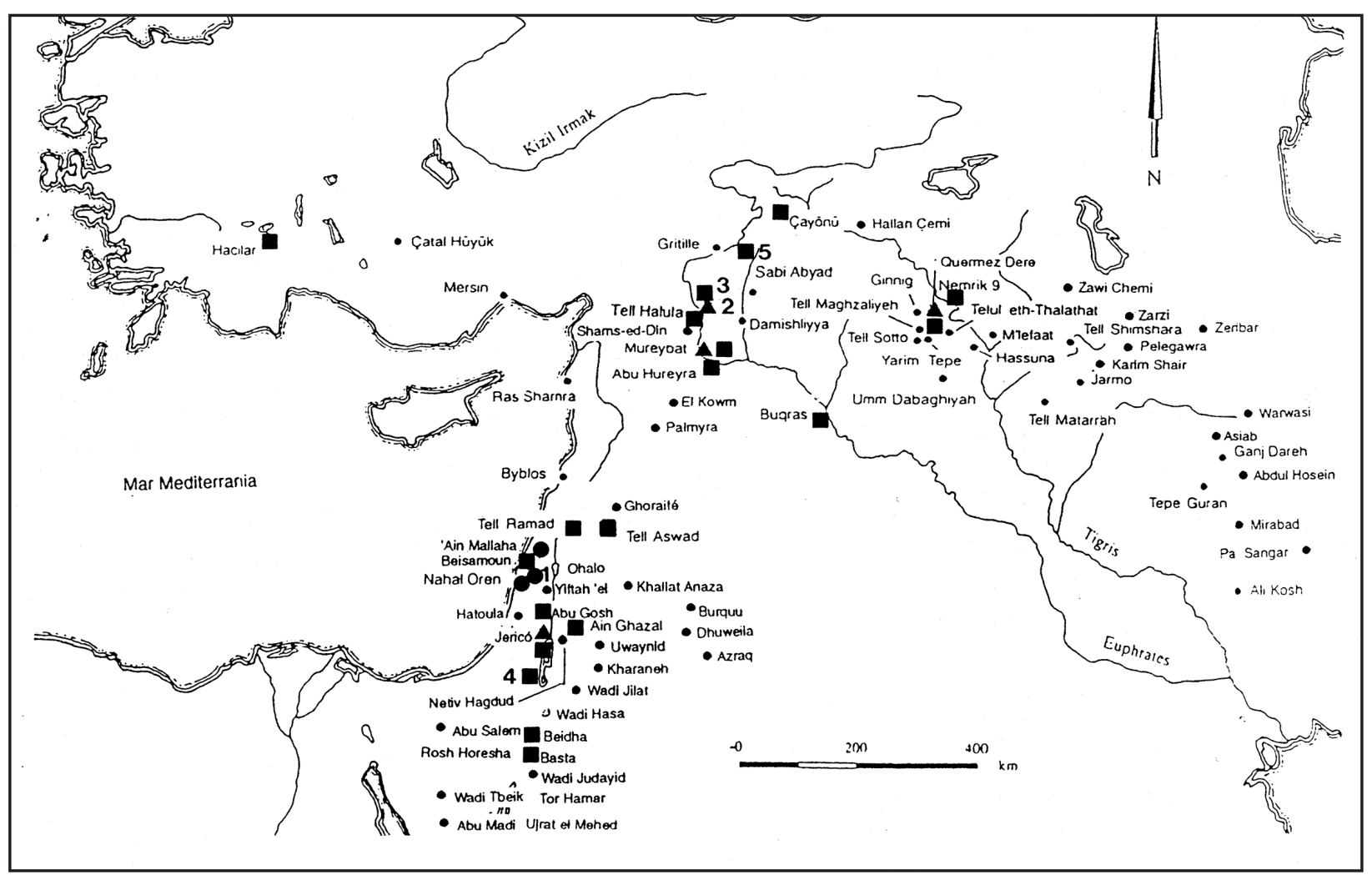

Figura 2.- Principales yacimientos natufienses y precerámicos citados en el texto (1: Hayonim, 2: Jerf el Ahmar, 3: Djad'e, 4: Nahal Hemar y 5: Nevali Cori) (círculos: yacimientos natufienses; triángulos: yacimientos del PPNA y cuadrados: yacimientos del PPNB (a partir de Saña, 1999, Figura 1).

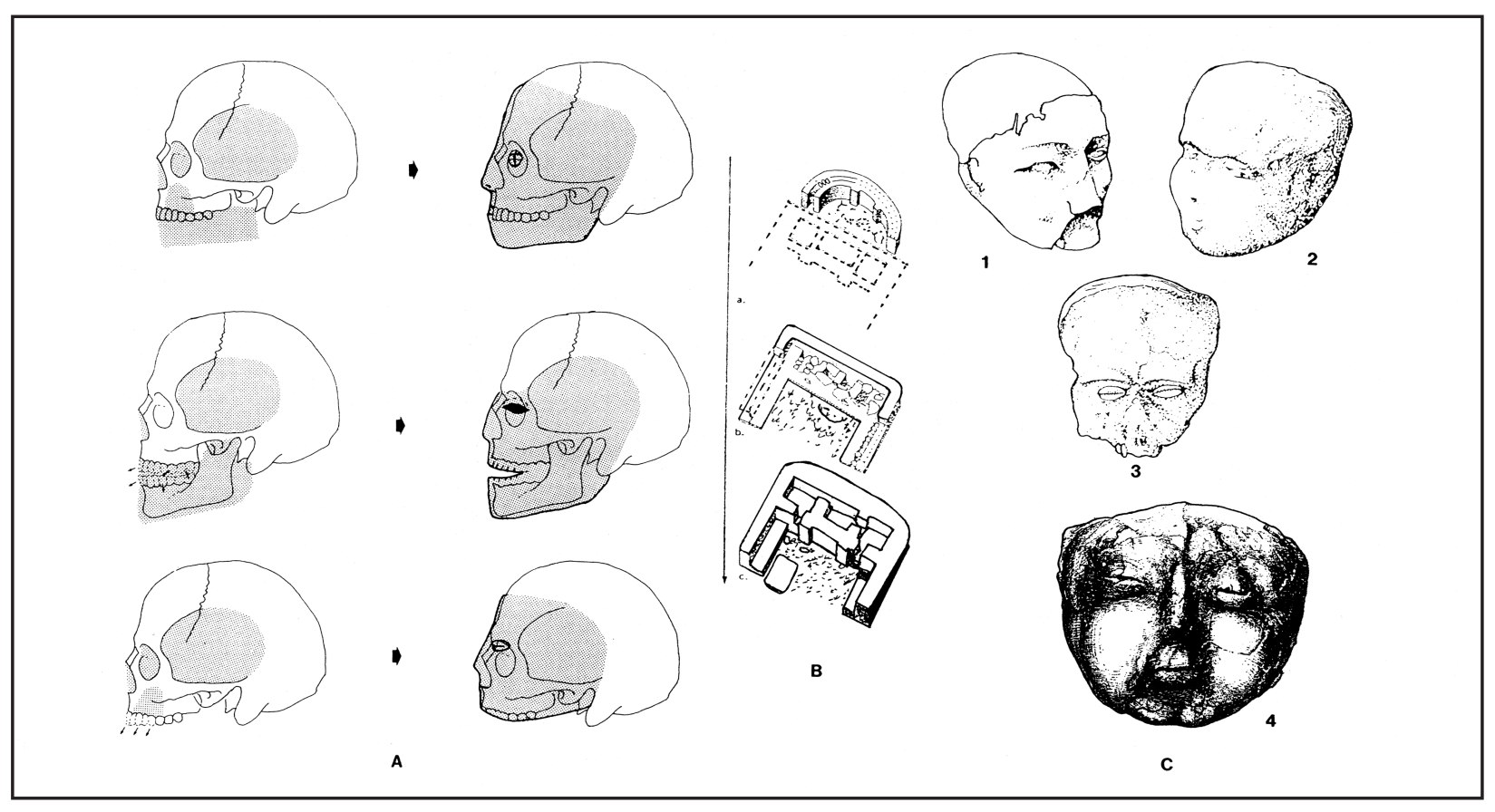

Figura 3.- A: Reconstrucción esquemática de los métodos de modelado de cráneos de Jericó (superior), Beisamoun (centro) y Kfar Hahoresh (inferior). A la izquierda, métodos de modificación de los huesos en el premodelado (extracción de los dientes e inserción de las capas basales de escayola) y a la derecha, resultado final en relación con el cráneo. B: "Edificio de los cráneos" de Çayönü; C: Cráneos modelados de Jericó (1-3) y Beisamoun (4) (Goren, Goring-Morris y Segal, 2001, Figura 17; Molist, 1992, 245; Pardo, 1999, 340 y 350 y Kuijt y Goring-Morris, 2002, Figura 10, c). 

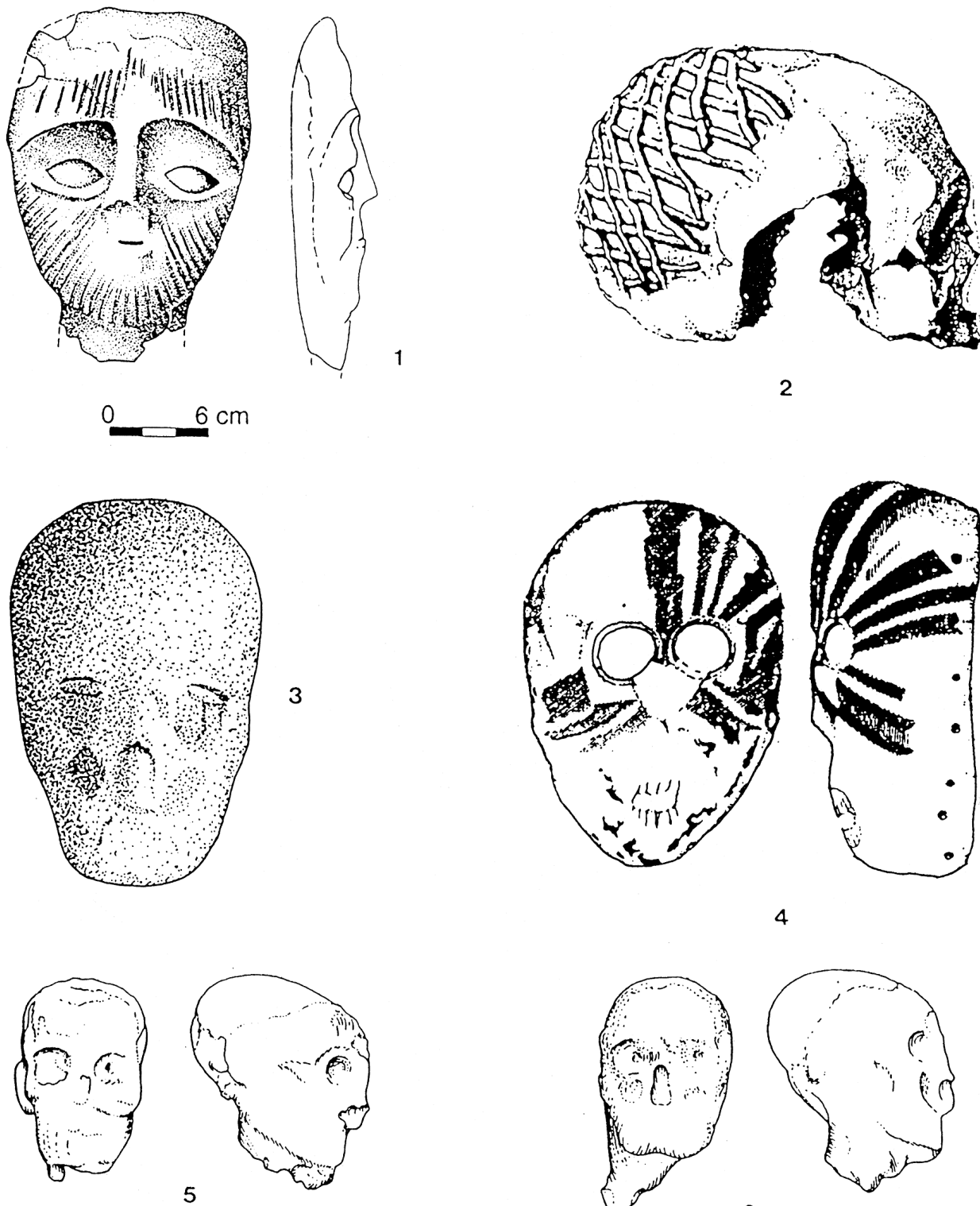

4
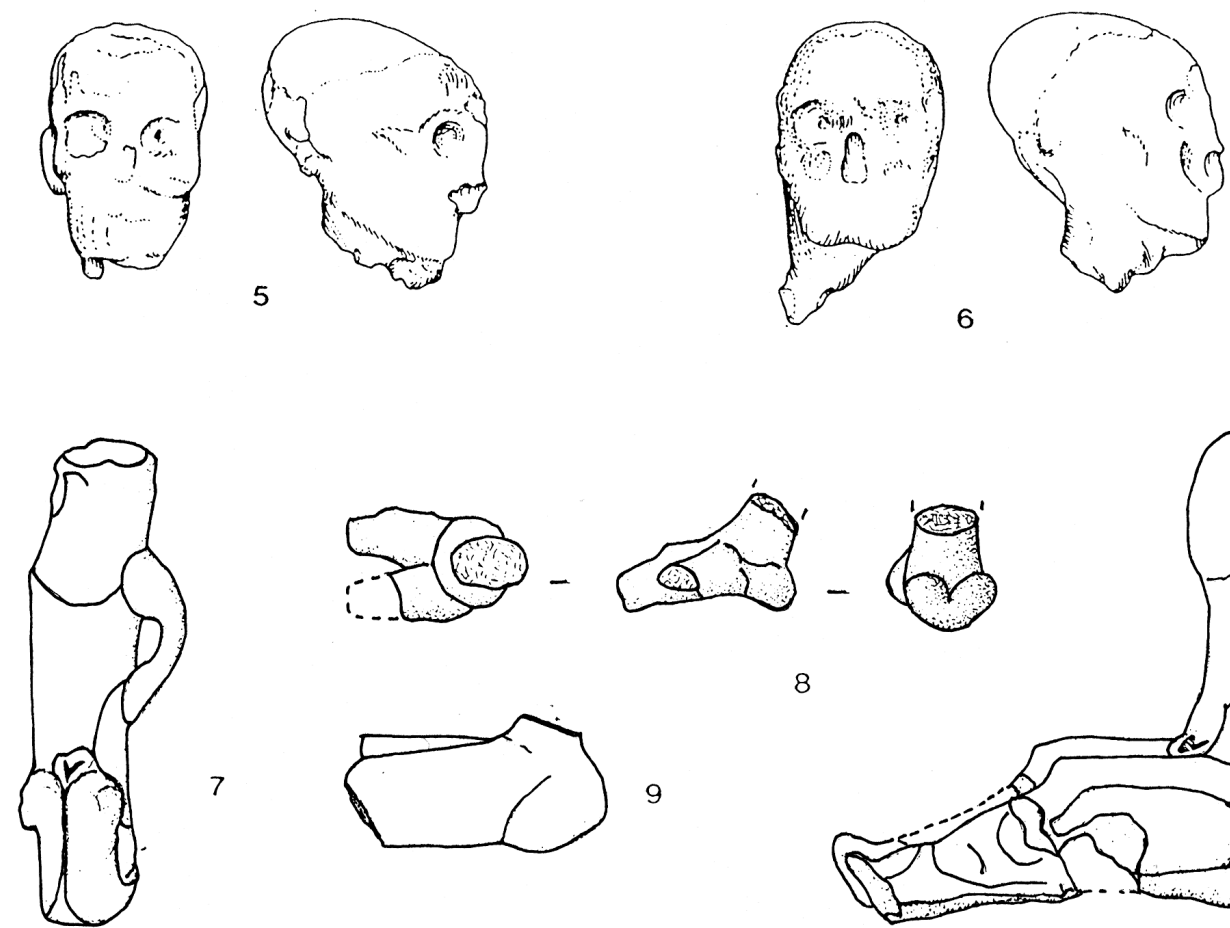

8
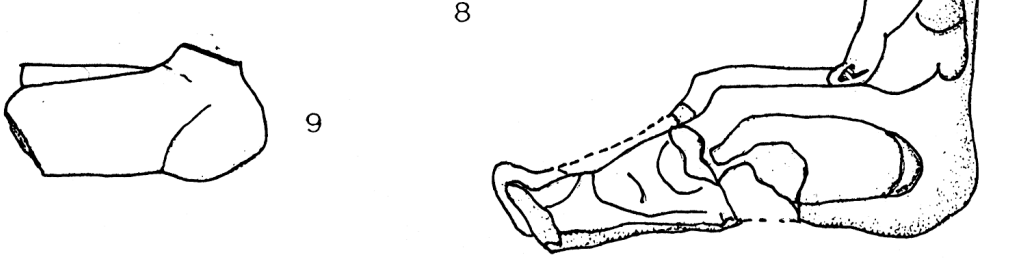

10

Figura 4.- Cabeza modelada en yeso de Jericó (1); cráneos humanos modelados de Nahal Hemar (2) y Tell Ramad (3, 5 y 6); máscara de Nahal Hemar (4) y estatuillas-soporte de cráneos humanos de Tell Ramad (7-10) (Mellaart, 1975, 62-63; Cauvin, 1994, 150 y 156 y Pardo, 1999, 130 y 328). 


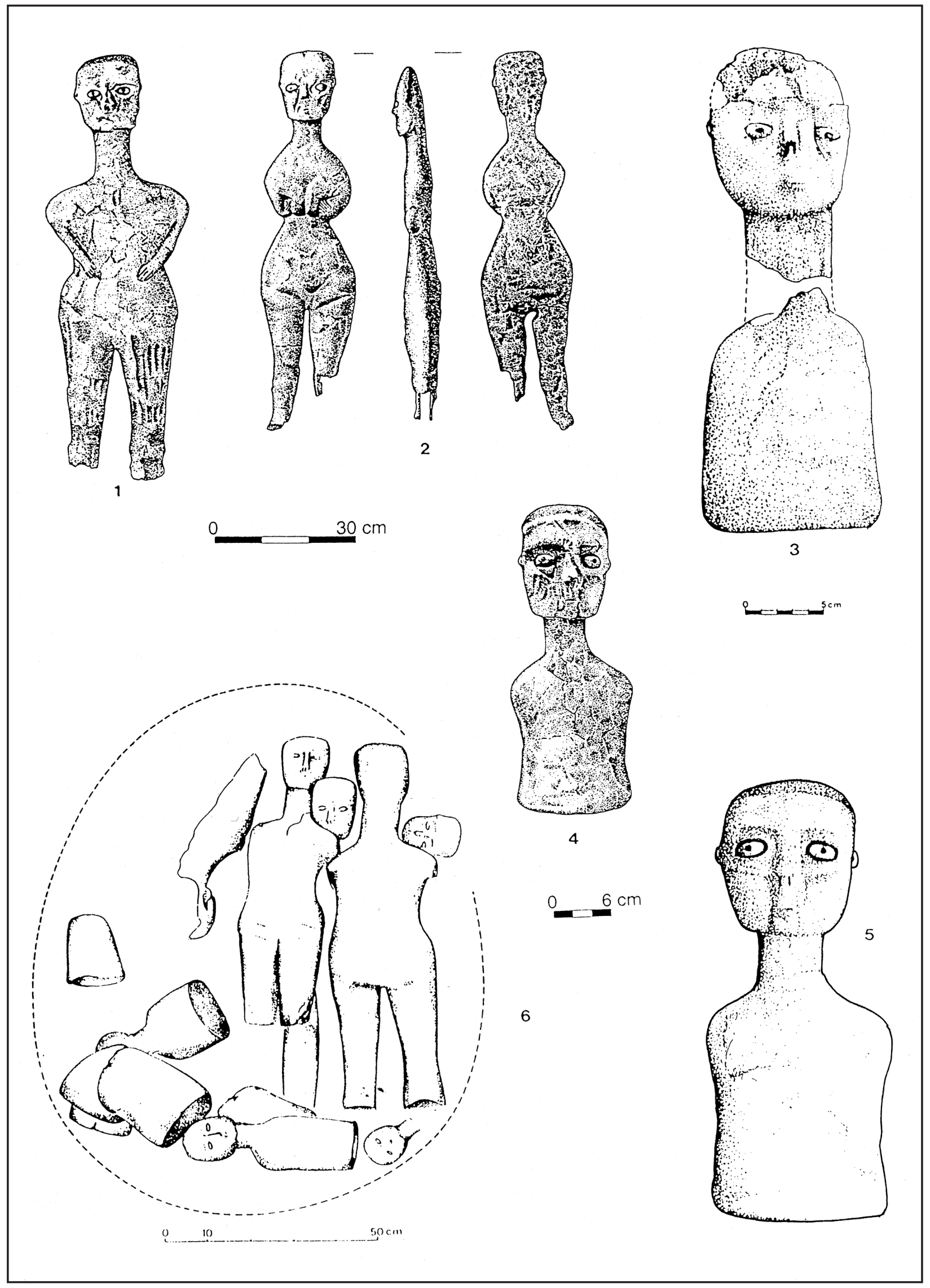

Figura 5.- Estatuaria de 'Ain Ghazal. Fosa del PPNB medio (6); estatuas de cuerpo entero (1-2) y bustos (3-5) (Cauvin, 1994, 150 y Aurenche y Kozlowski, 1999, 237). 